\title{
Health Workers' Assessment of the Frequency of and Caring for Urinary and Fecal Incontinence among Female Victims of Sexual Violence in the Eastern Congo: An Exploratory Study
}

\author{
Gunnel Andersson', Berthollet Bwira Kaboru1 ${ }^{1 *}$, Annsofie Adolfsson ${ }^{1,2}$, \\ Edmond Ntabe Namegabe ${ }^{3}$ \\ ${ }^{1}$ School of Health and Medical Sciences, Fakultetsgatan 1, Örebro University, Örebro, Sweden \\ ${ }^{2}$ The Centre for Women's, Family and Child Health, Faculty of Health Sciences, Buskerud \& Vestfold University \\ College, Kongsberg, Norway \\ ${ }^{3}$ Faculty of Community Health and Development, Université Libre des Pays des Grands Lacs, Goma, Congo \\ Democratic Republic \\ Email: ${ }^{*}$ berthollet.kaboru@oru.se
}

Received 3 March 2015; accepted 15 April 2015; published 20 April 2015

Copyright (C) 2015 by authors and Scientific Research Publishing Inc.

This work is licensed under the Creative Commons Attribution International License (CC BY).

http://creativecommons.org/licenses/by/4.0/

(c) (i) Open Access

\section{Abstract}

Background: Throughout the long war that the Democratic Republic of Congo (DRC) has endured, women and children have been depicted as the primary victims of widespread sexual violence. In some settings women have been raped in entire villages, with devastating physical and psychological consequences, which include sexually transmitted infections such as HIV, trauma and fistulas, as well as social isolation and involuntary pregnancies. The aim of this study was to assess the prevalent perceptions of health professionals on the magnitude of urine and/or fecal incontinence among assaulted women, caused by sexual violence, as well as the opinions regarding the type of care provided to affected women. Methods: The study was part of a larger pilot study that had a cross-sectional design and a descriptive approach, which explored health professionals' views regarding their own levels of competence at responding to the health needs of victims of sexual violence, in the form of a semi-structured questionnaire. Results: 104 health workers responded to the questionnaire. Nurses reported seeing raped women more frequently on a day-to-day basis (69.2\%), in comparison to medical doctors and social workers $(11.5 \%)$. Urinary incontinence was common according to $79 \%$ of health workers, who estimated that up to $15 \%$ of the women affected experienced huge amounts of urine leakage. Only $30 \%$ of the care seekers underwent in

${ }^{*}$ Corresponding author.

How to cite this paper: Andersson, G., Kaboru, B.B., Adolfsson, A. and Namegabe, E.N. (2015) Health Workers' Assessment of the Frequency of and Caring for Urinary and Fecal Incontinence among Female Victims of Sexual Violence in the Eastern Congo: An Exploratory Study. Open Journal of Nursing, 5, 354-360. http://dx.doi.org/10.4236/ojn.2015.54038 
depth investigations, but the majority of the victims were not offered any further examination or appropriate treatments. Conclusion: Urinary and fecal incontinence due to urogenital or colorectal fistulas among women exposed to sexual violence is a common in the specified setting, but lack of systematic investigation and appropriate treatment means that the quality of life of the victims may be negatively affected. An improvement in the ability of health workers to manage these complex diagnoses is urgently needed, as well as adequately equipping health services in the affected settings.

\section{Keywords}

Sexual Violence, Fistulas, Urinary Incontinence, Fecal Incontinence, Congo

\section{Introduction}

The Democratic Republic of Congo (DRC) is a country that has been blighted by war for nearly 20 years. This war has been labeled "the forgotten holocaust" [1] owing to the fact that approximately 8 million people have been killed [2] and as many as 5 million people displaced [1]. This war is also known for the widespread sexual violence against women and girls, which occur. Brutality and sexual violence have been strategically used as weapons in order to break down entire communities [3] [4]. In some settings, women in entire villages have been raped by armed groups. Significant proportions of these victims of sexual violence choose to keep silent and do not seek medical care or other assistance in dealing with their awful experiences. This is mainly due to the fact that it is considered as a "social death" and for fear of revenge from the abuser, particularly when perpetrator is known by the victim, or in the case that he/she (the abuser) is an influential person such as a military official or administrative authority, etc. [5]

The consequences of rape and even gang rapes on the victims' health are numerous, such as an increased risk of sexually transmitted infections (STIs), for example HIV. This is even more alarming given that it has been estimated that the military forces in this African region have one of the highest rates of STIs of any military group in the world. According to estimates, up to $60 \%$ of soldiers and other fighters in the region are infected with HIV [4]. Despite this, studies have shown that only $30 \%$ of women victims of sexual violence undergo postexposure prophylactic (PEP) treatment of HIV [6]. Extraordinarily brutal sexual abuse has been reported, including torture and the forcing of objects into the vagina, such as knives, guns and bayonets, resulting in unbearable trauma for the victims, both psychological and physical, and a risk of genital fistulas. A fistula is an abnormal passage between the vagina and the bladder or/and rectum, and it leads to both urinary and fecal leakage with negative consequences on the quality of life and social life, as well as physical burdens [7]. Clinical studies have demonstrated that at least $5 \%$ of the assaulted women had fistulas [8]. A figure that may have been underestimated, as Longombe (2008) found in a period between April 2003 to June 2006 that out of a group of 4715 women and girls who had been exposed to sexual violence, 702 (15\%) had genital fistulas [3].

Despite the overwhelming devastating incidence of sexual violence in DRC there are only a limited number of published studies, which overwhelmingly focus on clinical management and care issues, including the management of fistulas and social psychological aspects [3] [9]. Such clinical data is often incomplete and reveals only the tip of the iceberg. This is why it is important to elucidate the health workers' assessment of the magnitude of the problem and the ways in which they are currently assisting women with urine and/or fecal incontinence due to fistulas.

\section{Aim}

The aim of this study was to assess health professionals' perceptions of the magnitude of the problem of urine and/or fecal incontinence, caused by to sexual violence, and the care provided to the affected women.

\section{Materials and Methods}

\subsection{Study Design}

This study adopted a cross-sectional design with a descriptive approach. It is a part of a larger pilot study, exploring 
health professional's views on their own competence levels in responding to health needs of victims of sexual violence.

\subsection{Study Population and Sampling Procedure}

The study population consisted of health workers (clinicians and social workers) involved in the care of victims of sexual violence in the Karisimbi and Goma Health Districts, North-Kivu province, in Eastern DRC. The respondents were medical doctors, nurses, midwives and social workers employed in hospitals, health centers, antenatal care facilities, and Non-Governmental Organizations (NGOs).

A multistage sampling procedure combined with a convenience sampling method was used to collect the data. The study used an exhaustive sampling approach, according to which all available staff involved in the care of victims of sexual violence were to be targeted per institution (health facility or NGO), but a minimal requirement was that at least 2 health workers per institution should be interviewed. The steps that characterized this process included: 1 ) identifying the hospitals and health centers that are known to take care of many victims of sexual violence; 2) targeting antenatal consultation centers and/or gynecological and obstetrics' departments in these health centers and hospitals; 3) identifying NGOs conducting activities to support rape victims in the targeted health districts; 4) selecting and interviewing available (and consenting) health care personnel and NGOs workers. Using information from the Provincial Health Inspection Office, 36 institutions caring for victims of sexual violence were identified, of which 20 were health facilities (public and private health facilities) and 16 were philanthropic organizations (NGOs).

\subsection{Data Collection and Analysis}

The data was collected with the help of a semi-structured questionnaire developed specifically for the study by the research team. The content of the questionnaire included respondents' socio-demographic information, questions on the frequency of encounters between the respondents and victims of sexual violence, on the kind of health-related needs that the assaulted women experienced, on whether the health workers perceived themselves as competent or not, and on availability of specific services, such as urinary incontinence related investigation, treatment services and abortion, etc.

The questionnaire was pre-tested on health staff at the Kirotshe Hospital that belongs to a neighboring health district. Ten research assistants (interviewers) with previous experience in field surveys were chosen to conduct the interviews; they were trained for two days to become acquainted with the study's objective and the data collection tools. The data collection took one week to be completed. The collected data was coded, entered and analyzed in IBM SPSS 20 software. Chi-square and Fisher Exact (F-exact) tests were used where appropriate to check the significance of statistical differences of categorical variables.

\subsection{Ethical Considerations}

The study was approved by the Ethical committee at the "Université Libre des Pays des Grands Lacs” (ULPGL Goma), by the Mayor of the City of Goma and by the Chief Medical Officer of the Provincial Health Inspectorate of North-Kivu province. Before participation in the study, the purpose of the study was presented and explained to the respondents. They were guaranteed that any findings would be dealt with the upmost confidentiality and that their names would not appear anywhere in the data, nor the subsequent reports. The respondents were also told that they were free to stop their participation and withdraw from the study anytime during the interview. In case of agreement, the respondents were requested to sign their consent prior to completing the interview questionnaire.

\section{Results}

\subsection{Respondent's Socio-Demographics Characteristics}

A total of 104 health and social workers responded to the questionnaire. The respondents were predominantly young adults with a dominance of the age group between 15 to 44 years (82.7\%). The mean age was $37 \pm 9.4$ years. Furthermore, the respondents consisted of a majority of males (Table 1).

The majority of the respondents were high education graduates. Most of them were nurses (Table 2) working in health facilities (84.6\%) having in average worked for 6 years (5.68 \pm 6.71$)$. 
Table 1. Age and gender of respondent.

\begin{tabular}{ccc|}
\hline Age of Respondent & Frequency & Percent \\
\hline $15-29$ & 23 & 22.1 \\
$30-44$ & 62 & 59.6 \\
$45-59$ & 18 & 17.3 \\
60 and above & 1 & 1 \\
Total & 104 & 100 \\
\hline Sex of Respondent & Frequency & Percent \\
\hline Male & 79 & 7.0 \\
Female & 25 & 24.0 \\
Total & 104 & 100 \\
\hline
\end{tabular}

Table 2. Education level and profession of the respondents.

\begin{tabular}{ccc}
\hline Education Level & Frequency & Percent \\
\hline Secondary & 26 & 25 \\
University & 78 & 75 \\
Total & 104 & 100 \\
\hline Profession & Frequency & Percent \\
\hline Medical doctors & 13 & 12.5 \\
Nurses & 73 & 11.5 \\
Social workers & 12 & 11.5 \\
Social Counselors & 1 & 1.0 \\
Midwife & 1 & 1.0 \\
Managers of NGO & 4 & 3.8 \\
Total & 104 & 100 \\
\hline
\end{tabular}

Nurses represented the professional group that reported meeting the raped women more often (69.2\%) on daily basis, as compared to medical doctors and social workers (11.5\%). Eight percent of the nurses stated that they took care of approximately one raped women a day while 27.5 percent reported having met them about twice a week. Others stated that they had met these victims more seldom (sometimes as infrequently as once a month less).

The respondents described the women's needs as being mostly of a gynecological nature with additional psychosocial issues (17.3\%), pre-natal care (12.5\%) and abortion related issues (6.7\%).

\subsection{Urinary Incontinence}

Seventy-nine percent of the respondents answered that it was often or very often, that the women who seek care due to sexual violence report experiencing urinary incontinence (UI). The respondent's opinion was that most of the women had rather minor amounts of leakage that rarely occurred. Nevertheless, 15.4 percent of the women were reported to have huge amounts of leakage that occurred frequently.

The opinion of the respondents was that only approximately 30 percent of the women had some form of thorough investigation of the UI and one third of the women required paths of different kinds as protection for the urinary leakage (Table 3). 
Table 3. Frequency of complaints, investigation and protection in the case of urine and fecal incontinence.

\begin{tabular}{lcccc}
\hline \multirow{2}{*}{ Health workers' responses } & \multicolumn{2}{c}{ Urinary incontinence } & \multicolumn{2}{c}{ Fecal incontinence } \\
\cline { 2 - 4 } & Frequency & Percent & Frequency & 58 \\
\hline $\begin{array}{l}\text { Estimated frequency of patients (\%) with the complaint } \\
\text { (often/very often }\end{array}$ & 82 & 79 & 61 & 28.8 \\
$\begin{array}{l}\text { Estimated frequency of patients (\%) with the complaint } \\
\text { (often/very often }\end{array}$ & 33 & 31.7 & 30 & 28.8 \\
$\begin{array}{l}\text { Estimated frequency of patients (\%) with the complaint } \\
\text { (often/very often }\end{array}$ & 32 & 30.8 & 30 \\
\hline
\end{tabular}

\subsection{Fecal Incontinence}

More than half of the respondents (58\%) described that it is often or very often that the raped women reported fecal incontinence (FI). Even in this respect, most of the women (71\%) did not access incontinence protection for their fecal leakage and the majority did not go through any kind of in-depth investigation in order to diagnose fistula or other disorders (Table 3). The investigations available that were cited included mainly Methylene blue testing with urinary catheter, transrectal ultrasound and manual exploration by rectal touch.

Thirty-five percent of the respondents were aware of a treatment that was available for rape victims who experienced fecal incontinence. The treatments that were mentioned were: antiretroviral treatments for those suspected to be HIV positive, antibiotic therapy, antiseptic bath seat and painkillers. Transfer to specialized centers for surgical reparation was frequently mentioned.

\section{Discussion}

This exploratory study aimed at assessing health professionals' views regarding the frequency of urinary and fecal incontinence amongst patients who suffered sexual violence, as well as reviewing the services provided to the victims in terms of protection and investigation. This study was part of a larger pilot study with the focus on health care and social workers' experiences of taking care of female victims of sexual violence in DR Congo. The respondents in the study were mainly nurses with a working experience of up to 6 years. According to the health professionals, both urinal and fecal incontinence are a common problem as a result of sexual violence and rape. This incontinence is mostly due to urogenital and colorectal fistulas, resulting from the extremely brutal experiences that the women have undergone. Studies have reported that about 5 - 15 percent of the women experienced fistulas [3] [10], approximately one out of every 10 raped victims. This high prevalence has devastating consequences for the individuals, such as, hygiene problems, humiliation, sadness and often even rejection and divorce as a result as well as social isolation [7] [11].

Urinary and fecal incontinence due to fistula are treatable conditions [7] but unfortunately very few of the women are given the opportunity to undergo an appropriate investigation or examination for their urinal and/or fecal incontinence, which according to Abrams and colleagues, is the first step towards treatment [12].

In this study, the majority of the women with urinary as well as fecal incontinence did not undergo any further investigation. Incontinence is not directly a life-threatening condition unlike other common devastating diseases in the DR Congo, such as HIV, tuberculosis and malaria etc. [13], and perhaps this is one of the reasons that health services do not consider the issue of incontinence a priority. Another reason for lack of appropriate treatments for incontinence that has been identified (among the elderly), is deficient competence among health personal [14] as well as patients [15]. Lack of definitive treatment(s) or cure can also be a constraint: if there is no expectation that a treatment or cure is available or effective, it is less likely that a patient will be offered, or indeed informed of such a treatment.

Fistula surgery is an advanced treatment option and that is not available in all settings or in every hospital. There are however specialized hospitals which exist in the DRC, such as the Panzi Hospital in South Kivu (which is a neighboring province to our study setting), which offers treatment to women with fistulas caused by obstetrical problems as well as violence and rape. It is therefore of paramount importance that women suffering from fistulas are identified, so that they can be referred and treated. Another problem is that a non-negligible proportion of raped women do not seek any help at all, or endure a considerable delay before seeking health care, as was identified in a study by Bartels and colleagues, who found that health seeking delay could be as long as 
10 months [16]. Identified reasons included waiting for symptoms to develop or worsening, lack of means to access to medical care or fear for stigma [16]. The consequences of the fear of seeking care are that the women miss the opportunity of conservative treatment for fistulas [7] as well as prophylactic treatment for STI infections as HIV. In order to reverse this situation, intensive and persistent community mobilization is called for to fight stigma and encourage disclosure amongst the affected women.

It is important to increase the health professional's knowledge about the consequences of and enhance their skills to cater for, the need of those affected by sexual violence which unfortunately affects a large number of the population in the DRC. This is critical in supporting these vulnerable women and strengthening them in their social situations, but also in identifying the women that are in critical need of treatment or of some form of protective aid.

In an earlier study, we found that 45 percent of the women who had been raped, had been in fact been raped by men from their own villages and that there was a tendency to "normalize" sexual violence in communities [17]. Such a trend is a shift from earlier studies such as by Bartels et al. (2012) who found that the majority of the perpetrators were soldiers or men in uniforms [18]. Irrespective of the category of the offenders, it is important to promote an emotional understanding for these victims in society and support them in seeking professional medical help for their injuries.

\section{Conclusion}

Urinary and fecal incontinence due to urogenital or colorectal fistulas is a common complication experienced by women who have been exposed to sexual violence and rape in DRC. However, the majority of victims do not get the opportunity for a deeper investigation or examination, and miss the opportunity of adequate treatment. It is of urgent importance to increase health personnel's knowledge and abilities in managing these victims.

\section{Acknowledgements}

The authors are grateful to the Board of the Faculty of Medicine and Health at Örebro University for providing financial support (internationalization grant 2013) that permitted this pilot project to be launched. They also thank the Swedish Foundation for International Cooperation in Research and Higher Education (STINT) for funding the continuation of the collaboration with the ULPGL through an institutional grant (grant number IB2014-5630). Thanks to the ten research assistants who assisted in carrying out the interviews.

\section{References}

[1] Nyago, K. (2003) Congo-Kinshasa: The Forgotten Holocaust. In the Monitor, Kampala.

[2] Coghlan, B. Brennan, R.J., Ngoy, P., Dofara, D., Otto, B., Clements, M. and Stewart, T. (2006) Mortality in the Democratic Republic of Congo: A Nationwide Survey. The Lancet, 367, 44-51. http://dx.doi.org/10.1016/S0140-6736(06)67923

[3] Longombe, A.O., Claude, K.M. and Ruminjo, J. (2008) Fistula and Traumatic Genital Injury from Sexual Violence in a Conflict Setting in Eastern Congo: Case Studies. Reproductive Health Matters, 16, 132-141. http://dx.doi.org/10.1016/S0968-8080(08)31350-0

[4] Omba Kalonda, J.C. (2008) Sexual Violence in the Democratic Republic of Congo: Impact on Public Health? Medecine tropicale, 68, 576-578.

[5] Harvard Humanitarian Initiative (2010) “Now the World is Without Me”: An Investigation of Sexual Violence in Eastern Democratic Republic of Congo. In: A Report by the Harvard Humanitarian Initiative with Support from Oxfam America, Harvard Humanitarian Initiative \& Oxfam International, Boston, 32-38.

[6] Wakabi, W. (2008) Sexual Violence Increasing in Democratic Republic of Congo. The Lancet, 371, 15-16. http://dx.doi.org/10.1016/S0140-6736(08)60051-3

[7] De Ridder, D., et al. (2009) Fistulas in the Developing World. In: Abrams, P., et al., Eds., Incontinence, Health Publications Ltd., Paris.

[8] Onsrud, M., et al. (2008) Sexual Violence-Related Fistulas in the Democratic Republic of Congo. International Journal of Gynecology \& Obstetrics, 103, 265-269. http://dx.doi.org/10.1016/j.ijgo.2008.07.018

[9] Steiner, B., Benner, M.T., Sondorp, E., Schmitz, U.M. and Rosenberger, S. (2009) Sexual Violence in the Protracted Conflict of DRC Programming for Rape Survivors in South Kivu. Conflict and Health, 3, 3-12. 
[10] Onsrud, M., et al. (2008) Sexual Violence-Related Fistulas in the Democratic Republic of Congo. International Journal of Gynecology \& Obstetrics, 103, 265-269. http://dx.doi.org/10.1016/j.ijgo.2008.07.018

[11] Kelly, J.T., Betancourt, T.S., Mukwege, D., Lipton, R. and Vanrooyen, M.J. (2011) Experiences of Female Survivors of Sexual Violence in Eastern Democratic Republic of the Congo: A Mixed-Methods Study. Conflict and Health, 5, 25-25. http://dx.doi.org/10.1186/1752-1505-5-25

[12] Abrams, P., et al. (2009) Incontinence in 4th International Consultation on Incontinence. Health Publication Ltd., Paris.

[13] WHO (2004) Global Burden of Disease 2004 Update: Disability Weights for Diseases and Conditions. WHO, Geneva.

[14] Teunissen, D., et al. (2006) Urinary Incontinence in the Elderly: Attitudes and Experiences of General Practitioners. A Focus Group Study. Scandinavian Journal of Primary Health Care, 24, 56-61. http://dx.doi.org/10.1080/02813430500417920

[15] Andersson, G., Johansson, J.-E., Nilsson, K. and Sahlberg-Blom, E. (2008) Accepting and Adjusting: Older Women’s Experiences of Living with Urinary Incontinence. Urologic Nursing, 28, 115-121.

[16] Bartels, S.A., et al. (2012) Demographics and Care-Seeking Behaviors of Sexual Violence Survivors in South Kivu province, Democratic Republic of Congo. Disaster Medicine and Public Health Preparedness, 6, 393-401. http://dx.doi.org/10.1001/dmp.2012.66

[17] Kaboru, B.B., Andersson, G., Borneskog, C., Adolfsson A. and Namegabe, E.N. (2014) Knowledge and Attitudes toward Sexual Violence in Conflict-Affected Rural Communities in the Walikale District, DR Congo: Implications for Rural Health Services. Annals of Public Health and Research, 1, 1009-1015.

[18] Bartels, S., et al. (2013) Militarized Sexual Violence in South Kivu, Democratic Republic of Congo. Journal of Interpersonal Violence, 28, 340-358. http://dx.doi.org/10.1177/0886260512454742 